\title{
TRPC3 Channels Are Necessary for Brain-Derived Neurotrophic Factor to Activate a Nonselective Cationic Current and to Induce Dendritic Spine Formation
}

\author{
Michelle D. Amaral and Lucas Pozzo-Miller \\ Department of Neurobiology, Civitan International Research Center and McKnight Brain Institute, University of Alabama at Birmingham, Birmingham, \\ Alabama 35294
}

\begin{abstract}
Brain-derived neurotrophic factor (BDNF) exerts prominent effects on hippocampal neurons, but the mechanisms that initiate its actions are poorly understood. We report here that BDNF evokes a slowly developing and sustained nonselective cationic current $\left(I_{\mathrm{BDNF}}\right)$ in CA1 pyramidal neurons. These responses require phospholipase $\mathrm{C}, \mathrm{IP}_{3}$ receptors, $\mathrm{Ca}^{2+}$ stores, and $\mathrm{Ca}^{2+}$ influx, suggesting the involvement of transient receptor potential canonical subfamily (TRPC) channels. Indeed, $I_{\mathrm{BDNF}}$ is absent after small interfering RNA-mediated TRPC3 knockdown. The sustained kinetics of $I_{\mathrm{BDNF}}$ appears to depend on phosphatidylinositol 3-kinase-mediated TRPC3 membrane insertion, as shown by surface biotinylation assays. Slowly emerging membrane currents after theta burst stimulation are sensitive to the scavenger TrkB-IgG and TRPC inhibitors, suggesting $I_{\mathrm{BDNF}}$ activation by evoked released of endogenous, native BDNF. Last, TRPC3 channels are necessary for BDNF to increase dendritic spine density. Thus, TRPC channels emerge as novel mediators of BDNF-mediated dendritic remodeling through the activation of a slowly developing and sustained membrane depolarization.
\end{abstract}

Key words: CA1 pyramidal neuron; hippocampus; TrkB receptor; biolistic transfection; surface biotinylation; confocal microscopy; organotypic slice culture; siRNA-mediated knockdown; theta-burst stimulation

\section{Introduction}

Brain-derived neurotrophic factor (BDNF), a member of the neurotrophin family, is a potent modulator of activity-dependent synaptic plasticity in the CNS (Poo, 2001). Activated neurotrophin Trk receptors trigger three signaling cascades, phospholipase $\mathrm{C} \gamma(\mathrm{PLC} \gamma)-\mathrm{IP}_{3}$, Ras-Raf-extracellular signal-regulated kinase (ERK), and phosphatidylinositol 3 (PI3) kinase, all of which have been implicated in the varied actions of neurotrophins, ranging from modulation of gene expression, neuronal morphology, synaptic plasticity, and neurotransmitter release (Segal and Greenberg, 1996; Amaral et al., 2007). In addition to long-term modulation of ion channel expression, BDNF has been shown to evoke fast $\mathrm{Na}^{+}$currents through direct activation of $\mathrm{Na}_{\mathrm{v}} 1.9$ channels (Blum et al., 2002) and slower nonselective cationic currents mediated by transient receptor potential canonical subfamily 3 (TRPC3) channels (Li et al., 1999). Ion channels of

Received Aug. 2, 2006; revised Feb. 14, 2007; accepted Feb. 21, 2007.

This work was supported by National Institutes of Health Grants R01-NS40593 (L.P.-M.) and P30-HD38985 (University of Alabama at Birmingham Mental Retardation Research (enter) and by the Civitan International Foundation. L.P.-M. is a McNulty Civitan Scientist. We thank Chris Chapleau for assistance with spine density studies and initial observations of slow membrane currents induced by afferent stimulation. We are indebted to Dr. Takafumi Inoue (University of Tokyo, Tokyo, Japan) for continuous support of the acquisition and analysis software (TIWorkBench). We also thank Amgen (Thousand Oaks, (A) and Regeneron (Tarrytown, NY) for the supply of BDNF and TrkB-lgG, respectively.

Correspondence should be addressed to Dr. Lucas Pozzo-Miller, Department of Neurobiology, SHEL-1002, University of Alabama at Birmingham, 1825 University Boulevard, Birmingham, AL 35294-2182. E-mail: lucaspm@uab.edu.

DOI:10.1523/JNEUROSCI.5499-06.2007

Copyright $\odot 2007$ Society for Neuroscience $\quad$ 0270-6474/07/275179-11\$15.00/0
TRPC are activated by stimulation of $\mathrm{G}_{\mathrm{q}} / \mathrm{G}_{11}$-type G-proteincoupled receptors [e.g., group I metabotropic glutamate receptor (mGluR)] and by receptor tyrosine kinases such as Trk receptors, leading to PLC-mediated formation of $\mathrm{IP}_{3}$ and diacylglycerol (DAG) (Clapham, 2003). TRPC channels are widely expressed in brain (Mizuno et al., 1999), including the hippocampus (Li et al., 1999; Strubing et al., 2001). Thus, PLC-dependent, non-voltagegated cationic currents through TRPC channels are fundamentally novel forms of $\mathrm{Ca}^{2+}$ and $\mathrm{Na}^{+}$entry in central neurons, mediating the slower glutamate and neurotrophin responses through group I mGluRs (Kim et al., 2003) and TrkB receptors (Li et al., 1999), respectively.

Here, we present evidence that BDNF elicits a slowly developing and sustained nonselective cationic current in hippocampal CA1 pyramidal neurons. This tetrodotoxin (TTX)- and saxitoxin (STX)-insensitive current $\left(I_{\mathrm{BDNF}}\right)$ required functional Trk receptors, PLC activity, $\mathrm{IP}_{3}$ receptors $\left(\mathrm{IP}_{3} \mathrm{Rs}\right)$, full intracellular $\mathrm{Ca}^{2+}$ stores, and extracellular $\mathrm{Ca}^{2+}$, suggesting the involvement of TRPC channels. Indeed, $I_{\mathrm{BDNF}}$ was absent in neurons loaded with anti-TRPC3 function-blocking antibodies or in those transfected with a small interfering RNA (siRNA) construct designed to knockdown the expression of TRPC3. BDNF also increased the levels of surface accessible TRPC3 in cultured hippocampal neurons with a requirement for PI3 kinase signaling and a time course that paralleled the activation of $I_{\mathrm{BDNF}}$, which was also blocked by a PI3 kinase inhibitor. The activation of a similar conductance by endogenously released BDNF was indicated by the blockade of slowly emerging membrane currents after theta 
burst stimulation (TBS) by the scavenger TrkB-IgG, as well as by Trk receptor and TRPC channel inhibitors. Last, siRNAmediated TRPC3 channel knockdown prevented the characteristic BDNF-induced increase of dendritic spine density in CA1 pyramidal neurons. In summary, TRPC channels emerge as novel mediators of BDNF-initiated dendritic remodeling through the activation of a slowly developing and sustained membrane depolarization.

\section{Materials and Methods}

Organotypic slice culture. All animal procedures strictly adhered to national and international guidelines for the ethical use of research animals, such as the Public Health Service (PHS) Policy on Humane Care and Use of Laboratory Animals, as described at http://grants.nih.gov/grants/olaw/ references/phspol.htm, and the Policies on the Use of Animals and Humans in Neuroscience Research, as described at the Society for Neuroscience website http://www.sfn.org/index.cfm?pagename = guidelines Policies_UseOfAnimalsandHumans. Last, the Institutional Animal Care and Use Committee of the University of Alabama at Birmingham reviews and approves all animal procedures described in the present report on an annual basis. Briefly, hippocampi were dissected from anesthetized postnatal day 7-11 Sprague Dawley rats (Harlan, Indianapolis, IN or Charles River Laboratories, Wilmington, MA) and cut transversely into $\sim 400$ $\mu \mathrm{m}$-thick slices using a custom-made wire slicer fitted with 20 - $\mu \mathrm{m}$-thick gold-coated platinum wire (Pozzo-Miller et al., 1995). Hippocampal slices were individually plated on Millicell-CM filter inserts (Millipore, Billerica, MA) and cultured in $36^{\circ} \mathrm{C}, 5 \% \mathrm{CO}_{2}, 98 \%$ relative humidity incubators (Thermo-Forma, Waltham, MA). Slices were maintained in culture media (Neurobasal-A plus B27; Invitrogen, Carlsbad, CA) containing $20 \%$ equine serum for the first $4 \mathrm{~d}$ in vitro (div). To avoid the confounding effects of hormones and growth factors in the serum, its concentration was gradually reduced over a period of $48 \mathrm{~h}$ starting at 4 $\operatorname{div}(24 \mathrm{~h}$ each in 10 and $5 \%$ serum). After a period of $24 \mathrm{~h}$ in serum-free media (Neurobasal-A plus B27), 7-10 div slices were used for electrophysiology and immunocytochemistry (Tyler and Pozzo-Miller, 2001). Some slice cultures remained in serum-containing culture media $(20 \%$ equine serum), as described in the original publications (Gahwiler, 1981; Yamamoto et al., 1989; Stoppini et al., 1991; Pozzo-Miller et al., 1993).

Primary culture of dissociated postnatal neurons. Hippocampi were dissected from anesthetized postnatal day 2 Sprague Dawley rats (Harlan or Charles River Laboratories) and dissociated in papain (Worthington, Lakewood, NJ) for $45 \mathrm{~min}$ at $37^{\circ} \mathrm{C}$. The tissue was triturated to obtain a single-cell suspension, and the cells were plated on dishes coated with poly-D-lysine/laminin and fed culture media (Neurobasal-A plus B27). Neurons were grown in $36^{\circ} \mathrm{C}, 5 \% \mathrm{CO}_{2}, 98 \%$ relative humidity incubators (Thermo-Forma). Cultures were maintained for 10-14 div before experimental procedures, with half of the medium changed every $4 \mathrm{~d}$.

Whole-cell intracellular recordings. Individual 7-10 div slices were transferred to a recording chamber mounted on a fixed-stage upright microscope (Axioskop FS; Zeiss, Oberkochen, Germany) and continuously perfused $(2 \mathrm{ml} / \mathrm{min}$ ) with artificial CSF (aCSF) at room temperature $\left(24^{\circ} \mathrm{C}\right)$ containing the following (in $\mathrm{mM}$ ): $124 \mathrm{NaCl}, 2 \mathrm{KCl}, 1.24$ $\mathrm{KH}_{2} \mathrm{PO}_{4}, 1.3 \mathrm{MgSO}_{4}, 17.6 \mathrm{NaHCO}_{3}, 2.5 \mathrm{CaCl}_{2}, 10$ glucose, and 29.2 sucrose (310-320 mOsm). aCSF was bubbled with $95 \% \mathrm{O}_{2} / 5 \% \mathrm{CO}_{2}, \mathrm{pH}$ 7.4. Superficial CA1 pyramidal neurons were visualized with a waterimmersion $63 \times$ objective [0.9 (NA) numerical aperture] using infrared differential interference contrast (IR-DIC) microscopy. Whole-cell intracellular recordings were performed as described (Pozzo-Miller et al., 1995; Pozzo-Miller, 2006). Briefly, unpolished patch pipettes contained the following (in mM): 120 Cs-gluconate (or K-gluconate), $17.5 \mathrm{CsCl}$ (or $\mathrm{KCl}$ ), $10 \mathrm{Na}$-HEPES, $4 \mathrm{Mg}$-ATP, $0.4 \mathrm{Na}$-GTP, $10 \mathrm{Na}_{2}$ creatine phosphate, and 0.2 Na-EGTA (280-290 mOsm), pH 7.2 (resistance of 3-4 M $\Omega$ ). Nominally calcium-free extracellular aCSF was prepared by replacing $\mathrm{CaCl}_{2}$ with an equimolar concentration of $\mathrm{MgCl}_{2}$. Some drugs were dissolved in DMSO ( $\leq 0.01 \%$ final concentration) and others directly into the aCSF or intracellular solution; vehicle controls using $0.01 \%$ DMSO were routinely performed yielding no effects on membrane currents or BDNF-induced responses. Membrane currents were recorded in the voltage-clamp mode at a holding potential of $-65 \mathrm{mV}$ using an Axoclamp 200B amplifier (Molecular Devices, Sunnyvale, CA), filtered at 2 $\mathrm{kHz}$, and digitized at $10 \mathrm{kHz}$. Recordings were accepted only if access (series) resistance was $\leq 30 \mathrm{M} \Omega$. CA1 neurons had whole-cell capacitances of $\sim 100 \mathrm{pF}$. Input resistance $\left(R_{\mathrm{i}}\right)$ was measured with hyperpolarizing voltage pulses $(50 \mathrm{~ms},-20 \mathrm{mV})$, and cells were discarded if any of those cell parameters $\left(C_{\mathrm{m}}, R_{\mathrm{i}}, R_{\mathrm{s}}\right)$ changed by $\geq 20 \%$ during the course of an experiment. Current-voltage relationships were estimated from slow voltage ramps between -85 and $+45 \mathrm{mV}(4 \mathrm{~s} ; 32.5 \mathrm{mV} / \mathrm{s})$ performed in the presence of TTX $(0.5 \mu \mathrm{M})$ and $\mathrm{Cd}^{2+}(200 \mu \mathrm{M})$ to prevent the firing of $\mathrm{Na}^{+}$- and $\mathrm{Ca}^{2+}$-dependent action potentials in distal dendrites that could escape voltage-clamp control. Electrophysiology data were acquired on a single G4 Macintosh computer (Apple Computers, Cupertino, CA) running custom-written software (TIWorkBench, kindly provided Dr. T. Inoue, Tokyo University, Tokyo, Japan). All of the chemicals used for these experiments were obtained from Sigma (St. Louis, MO), Calbiochem (San Diego, CA), or Tocris (Ellisville, MO).

Human recombinant mature BDNF (supplied by Amgen, Thousand Oaks, CA) was pressure applied from glass pipettes $(\sim 5 \mathrm{M} \Omega)$ using a Picospritzer-III (Parker Hannifin, Cleveland, OH). An application pipette was positioned $\sim 100 \mu \mathrm{m}$ above the slice and $\sim 200 \mu \mathrm{m}$ away from the soma of the CA1 neuron under recording, aimed at its apical dendrites within stratum radiatum $(\sim 150 \mu \mathrm{m}$ from the soma $)$ and against the direction of aCSF perfusion flow. This arrangement produced a stream of BDNF solution that overshoots the cell under recording and flows back over the slice, already diluted in the aCSF. Application of glutamate ( $100 \mu \mathrm{M}, 8 \mathrm{psi}, 9 \mathrm{~s})$ from similar pipettes was used to optimize this arrangement, yielding highly reproducible and stable transient membrane currents. In addition, food coloring was used to assess the spatial spreading of the applied solution over the slice. Pressure pulses of 30 psi lasting $25-30 \mathrm{~s}$ delivered a total volume of $2 \mu \mathrm{l}$ of solution from $\sim 5$ $\mathrm{M} \Omega$ glass pipettes. In most experiments, the pipette contained $100 \mu \mathrm{g} / \mathrm{ml}$ BDNF in $0.0001-0.1 \%$ BSA. The extracellular BDNF scavenger TrkBIgG $(1 \mu \mathrm{g} / \mathrm{ml}$; supplied by Regeneron, Tarrytown, NY; also from R \& D Systems, Minneapolis, MN) was used to estimate the effective BDNF concentration required for $I_{\mathrm{BDNF}}$ activation. To test for dose-response relationships, some pipettes contained 50 or $75 \mu \mathrm{g} / \mathrm{ml}$ BDNF in $0.0001 \%$ BSA. BDNF denatured by boiling (10 min; $100 \mu \mathrm{g} / \mathrm{ml})$, BSA alone $(0.0001$ or $0.1 \%)$, and aCSF were used as pressure application controls. NGF, neurotrophin 4 (NT-4), and NT-3 (Promega, Madison, WI) (100 $\mu \mathrm{g} / \mathrm{ml}$ in $0.0001 \% \mathrm{BSA}$ ) were applied in a similar manner.

Afferent fiber stimulation was performed with an extracellular patch pipette filled with buffered and oxygenated aCSF $(\sim 4 \mathrm{M} \Omega)$ positioned within CA1 stratum radiatum to stimulate Schaeffer collaterals. Square constant-current pulses of $100 \mu$ s duration were produced by an isolated stimulator (ISO-Flex; A.M.P.I., Jerusalem, Israel). High-frequency afferent stimulation was delivered as a theta burst pattern consisting of five bursts at $5 \mathrm{~Hz}$, each burst having four pulses at $100 \mathrm{~Hz}$. A subthreshold concentration of the $\mathrm{Na}^{+}$channel blocker TTX (10 nM) was included in the aCSF to reduce membrane excitability and prevent polysynaptic responses, common in organotypic slices. The aCSF contained the $\mathrm{GABA}_{\mathrm{A}}$ receptor antagonist picrotoxin $(50 \mu \mathrm{M})$, whereas the $\mathrm{K}^{+}$channels coupled to $\mathrm{GABA}_{\mathrm{B}}$ receptors were blocked by intracellular $\mathrm{Cs}^{+}$. The aCSF also contained the noncompetitive antagonists of AMPA and NMDA receptors, GYKI-52466 [4-(8-methyl-9H-1,3-dioxolo [4,5-h][2,3]benzodiazepin-5-yl)-benzenamine hydrochloride] $(20 \mu \mathrm{M})$ and MK-801 [(5S, 10R)-(+)-5-methyl-10,11-dihydro-5H-dibenzo [a,d] cyclohepten-5,10imine maleate] $(20 \mu \mathrm{M})$, respectively, as well as the antagonist of group I mGluRs LY-367385 [( $S)-(+)$ - $\alpha$-amino-4-carboxy-2-methylbenzeneacetic acid] (100 $\mu \mathrm{M})$; additional experiments were performed with the competitive antagonists CNQX (20 $\mu \mathrm{M})$ and D, L-APV $(50 \mu \mathrm{M})$. The constant-current intensity used for afferent stimulation (between 10 and $50 \mu \mathrm{A}$ ) was never larger than 10 times that required to evoke AMPA receptor-mediated fast EPSCs $(\sim 100-200 \mathrm{pA})$ at a holding potential of $-65 \mathrm{mV}$ in control aCSF.

Immunocytochemistry. Slices or cells were washed with PBS, and then fixed with $4 \%$ paraformaldehyde and $4 \%$ sucrose in phosphate buffer (PB) for 70 min. After rinsing with PBS containing $10 \mathrm{mM} \mathrm{NH}_{4} \mathrm{Cl}$ and then PBS alone, slices or cells were incubated with blocking and perme- 
abilization buffer ( $0.4 \%$ fetal goat serum and $0.1 \%$ Triton X-100 in PBS) for $1 \mathrm{~h}$ and subsequently incubated with primary antibodies (antiTRPC3; Alomone Labs, Jerusalem, Israel) diluted in blocking and permeabilization buffer. After incubation with FITC-conjugated secondary antibodies, slices or cells were incubated with blocking and permeabilization buffer and then incubated with NeuN (Millipore) primary antibodies. Slices were then incubated with Texas Red-conjugated secondary antibodies. Alternatively, biotinylated secondary antibodies were used in combination with avidin-conjugated Quantum dots (488 nm excitation, $525 \mathrm{~nm}$ emission; Invitrogen). Finally, slices were mounted, sealed with Vectashield (Vector Laboratories, Burlingame, CA), and imaged with a laser scanning confocal microscope equipped with argon and krypton lasers (FV300; Olympus Optical, Center Valley, PA) and oil-immersion lenses $(60 \times, 1.2 \mathrm{NA}$ or $100 \times, 1.4 \mathrm{NA})$. Controls were incubated with only primary or secondary antibodies.

Surface biotinylation. Primary hippocampal cultures 10-14 div were washed once with aCSF and then stimulated with BDNF in aCSF. SulfoNHS-SS linked biotin $(1.5 \mathrm{mg} / \mathrm{ml}$ in $1 \times$ PBS, $\mathrm{pH} 8.0)$ was then added to the neurons and incubated at $4^{\circ} \mathrm{C}$ for $45 \mathrm{~min}$. Excess biotin was quenched with $100 \mathrm{~mm}$ glycine, and then the cultures were washed with $1 \times$ PBS. The neurons were lysed with radioimmunoprecipitation assay buffer $(50$ mm Tris, $\mathrm{pH}$ 8.0, $150 \mathrm{~mm} \mathrm{NaCl}, 1 \%$ Nonidet P-40, 0.5\% sodium deoxycholate, and $0.1 \%$ SDS). Protein concentrations were determined via the Lowry method, and $1 \mathrm{mg}$ of each sample was added to streptavidin agarose (Pierce, Rockford, IL) and then incubated overnight at $4^{\circ} \mathrm{C}$. The streptavidin agarose was washed three times with lysis buffer, and samples were eluted by adding $2 \times$ Laemli's buffer (Bio-Rad, Hercules, CA) and then heating to $70^{\circ} \mathrm{C}$ for $30 \mathrm{~min}$. Proteins were separated on SDSPAGE gels, and Western blots with anti-TRPC3 antibodies (Alomone Labs) were conducted. The two bands detected in Western blots are not observed when the samples are preincubated with the control peptide antigen (HKLSE KLNPS VLRC, corresponding to residues 822-835 of mouse TRPC3; UniProtKB/Swiss-Prot accession number Q9QZC1). Anti-transferrin receptor (Zymed, San Francisco, CA) and anti-actin antibodies (Sigma) were used as loading controls for surface and intracellular proteins, respectively. Gels were scanned at $300 \mathrm{dpi}$ in a flatbed scanner, and pixel intensity was measured using the gel analysis tool of NIH ImageJ software. The intensity of TRPC 3 bands was normalized to the intensity of the transferrin receptor bands.

TRPC3 siRNA. siRNA oligos (Invitrogen) were designed to target TRPC3 channel subunits. The sequence of TRPC3 siRNA is as follows: Invitrogen-2476, sense sequence $5^{\prime}$ to $3^{\prime}$, GCACUCCAAGCAGUGACAU; antisense sequence $5^{\prime}$ to $3^{\prime}$, AUGUCACUGCUUGGAGUGC. Primary hippocampal neurons 10-14 div were transfected with $1 \mu \mathrm{g}$ of fluorescein-labeled siRNA using the Gene Silencer siRNA Transfection Reagent (Gene Therapy Systems, San Diego, CA). Following the suggestions of the manufacturer, GeneSilencer and siRNA were diluted with serum-free medium (Neurobasal plus B27) and then mixed together for $15 \mathrm{~min}$ at room temperature. To the cultured neurons, $1 \mathrm{ml}$ of serum-free medium was added, followed by the siRNA mixture. After $24 \mathrm{~h}$ at $36^{\circ} \mathrm{C}, 2$ $\mathrm{ml}$ of serum-free medium was added to the neurons. Four days later, the cultures were harvested and processed for Western blotting.

Particle-mediated gene transfer. Hippocampal slices were cotransfected with a plasmid encoding enhanced yellow fluorescent protein (eYFP) (Clontech, Mountain View, CA) and the TRPC3 siRNA oligos. A custom-modified Helios gene gun (Bio-Rad) was used to perform the biolistic transfection following established protocols (Lo et al., 1994; Alonso et al., 2004). Briefly, plasmid cDNA and siRNA oligos were precipitated onto $1.6 \mu \mathrm{m}$ colloidal gold at a ratio of $50 \mu \mathrm{g}$ of eYFP plasmid to $100 \mu \mathrm{g}$ of siRNA oligo to $25 \mathrm{mg}$ of gold. This mixture was coated onto Tefzel tubing using $0.06 \mathrm{mg} / \mathrm{ml}$ polyvinylpyrrolidone. Slices were bombarded using helium pressure at 100 psi at a distance of $15 \mathrm{~mm}$. For experiments using only eYFP, gene transfer was performed as above, except the plasmid encoding eYFP was precipitated onto $1.6 \mu \mathrm{m}$ colloidal gold at a ratio of $50 \mu \mathrm{g}$ of DNA to $25 \mathrm{mg}$ of gold.

BDNF and inhibitor treatments for confocal microscopy. Three days after particle-mediated gene transfer, the respective inhibitors were added to the culture media $30 \mathrm{~min}$ before BDNF (250 ng/ml) application. To facilitate penetration of the reagents, an additional $50 \mu \mathrm{l}$ of medium was gently placed on top of each slice. After $24 \mathrm{~h}$ of BDNF exposure, slices were fixed in $4 \%$ paraformaldehyde and $100 \mathrm{~mm}$ PB for $60 \mathrm{~min}$, rinsed in $\mathrm{PB}$, and mounted on glass slides using Vectashield (Vector Laboratories).

Confocal microscopy. A FluoView300 laser-scanning confocal microscope (Olympus Optical) fitted with a $100 \times, 1.4 \mathrm{NA}$ oil-immersion lens was used to acquire images of apical secondary and tertiary dendrites of eYFP-transfected CA1 neurons. eYFP and fluorescein-labeled siRNA were excited with the $488 \mathrm{~nm}$ line of the argon laser and detected using standard FITC filters. Optical sections in the $z$-axis were acquired at 0.1 $\mu \mathrm{m}$ intervals.

Spine density analysis. Dendritic spines were identified as small projections extending $\leq 3 \mu \mathrm{m}$ from the adjacent dendrite, as described previously (Pozzo-Miller et al., 1999; Tyler and Pozzo-Miller, 2001, 2003; Alonso et al., 2004). Spines were quantified on maximum-intensity projections of the $z$-stacks using NIH ImageJ software. To ensure that each spine was counted only once, their course was followed through the stack of $z$-sections. In addition, only those spines that appeared continuous with the parent dendrite were used for analysis. Spine density was calculated by quantifying the number of spines per length of imaged dendrite and then normalized to $10 \mu \mathrm{m}$ of dendritic length. Supplemental Table 1 (available at www.jneurosci.org as supplemental material) contains all of the measured parameters in the spine density analysis, including the total length of apical secondary and tertiary apical dendrites analyzed, the number of neurons and slices, and the coefficient of variance $(\mathrm{CV})$ of spine density values. Spine counts were performed "blindly" by an investigator unaware of the treatment groups.

Statistical analysis. Data were statistically analyzed using unpaired Student's $t$ test or ANOVA, followed by Newman-Keuls multiplecomparison post hoc test with Prism software package (GraphPad Software, San Diego, CA). $p<0.05$ was considered significant. Data are presented as mean \pm SEM; the SD of the mean was used to calculate the coefficient of variance $(\mathrm{CV}=$ mean/SD), which is given as a measure of consistency.

\section{Results}

BDNF induces a slow depolarizing membrane current, $I_{\mathrm{BDNF}}$, in CA1 pyramidal neurons through the activation of TrkB receptors

Long-term (minutes to hours) exposure to BDNF induces varied effects on hippocampal neurons, ranging from modulation of synaptic transmission and plasticity to structural changes of dendrites, spines, and presynaptic terminals (McAllister et al., 1999; Poo, 2001; Tyler et al., 2002b; Lu, 2003; Amaral et al., 2007). Conversely, brief $(<300 \mathrm{~ms})$ and highly targeted $(<20 \mu \mathrm{m})$ BDNF pulses have been shown to elicit transient EPSP-like membrane depolarizations through the direct activation of $\mathrm{Na}_{\mathrm{v}} 1.9$ channels (Kafitz et al., 1999; Blum et al., 2002). We chose to apply BDNF from picospritzer-controlled pipettes placed $\sim 100 \mu \mathrm{m}$ above hippocampal slice cultures to avoid pressure and mechanical artifacts. BDNF-containing pipettes were positioned over CA1 neuron dendrites within stratum radiatum, $\sim 200 \mu \mathrm{m}$ away from their cell bodies (Fig. $1 A$ ) to reproduce the spatiotemporal profile of a paracrine neuropeptide released from dense-core vesicles acting on perisynaptic receptors (Lessmann et al., 2003). Under these conditions, a single BDNF application (25-30 s) induced a delayed $(54 \pm 3.6 \mathrm{~s})$ and slowly developing inward current with an average amplitude of $577.23 \pm 41.07 \mathrm{pA}(n=24$ cells) in $\mathrm{Cs}^{+}$-filled CA1 pyramidal neurons held at $-65 \mathrm{mV}$ in the presence of TTX (500 nM) (Fig. 1B). These membrane currents, $I_{\mathrm{BDNF}}$, persisted for $13.03 \pm 2.11 \mathrm{~min}$ and were highly reproducible, because successive applications to the same cell (two to three; $20 \mathrm{~min}$ apart) evoked responses of similar amplitude $(607.7 \pm 19.98 \mathrm{pA} ; n=4 ; p=0.7703$ vs single application responses). The above responses were made in slices kept in serum-free media to avoid the confounding effects of hormones and growth factors in the serum; similar responses were also ob- 
served in slice cultures maintained in serumcontaining culture media (430.02 \pm $8.04 \mathrm{pA} ; n=4)$. A significant decrease in membrane input resistance indicated an increase in membrane conductance at the peak of the BDNF response $\left(R_{\mathrm{i}}=202.05 \pm\right.$ 12 vs $106.23 \pm 9.95 \mathrm{M} \Omega ; p<0.0001)$. The current-voltage $(I-V)$ relationship of $I_{\mathrm{BDNF}}$ was estimated by voltage ramp protocols ( $4 \mathrm{~s}$ from -85 to $+45 \mathrm{mV}$ ) applied before and near the peak of $I_{\mathrm{BDNF}}$ evoked in the presence of TTX ( $500 \mathrm{nM})$ and $\mathrm{Cd}^{2+}$ $(200 \mu \mathrm{M})$ to block voltage-gated $\mathrm{Na}^{+}$and $\mathrm{Ca}^{2+}$ channels, respectively. The contribution of AMPA and NMDA receptor currents during these voltage ramps was eliminated by inclusion of CNQX $(20 \mu \mathrm{M})$ and D,L-APV $(100 \mu \mathrm{M})$, respectively. The positive slope conductance estimated from a linear regression of each $I-V$ plot was $3.54 \pm 0.21 \mathrm{nS}(n=3)$. The average reversal potential of the subtracted BDNFinduced component of the current response to the voltage ramp was $27.96 \pm$ $6.32 \mathrm{mV}(n=3)$, indicative of a mixed cationic conductance (supplemental Fig. 1, available at www.jneurosci.org as supplemental material).

Consistent with the activation of an inward current at resting membrane potential, BDNF elicited a similarly delayed and slowly developing membrane depolarization in $\mathrm{K}^{+}$-filled neurons in the absence of TTX $(22.18 \pm 2.02 \mathrm{mV} ; n=9)$, which led to an increase in spontaneous action potentials and EPSPs (Fig. 1C). BDNF also caused a pronounced increase in the frequency of spontaneous miniature EPSCs (in TTX), without affecting their amplitude (Fig. 1B) (our unpublished observation), consistent with its known presynaptic actions on neurotransmitter release (Poo, 2001; Tyler et al., 2002a, 2006). Together, these observations directly demonstrate that BDNF has parallel actions on both sides of excitatory synapses, enhancing presynaptic transmitter release and directly activating a postsynaptic membrane depolarization.

The effects of BDNF on membrane conductance were confirmed to be specific, because vehicle alone (up to $0.1 \%$ BSA) or BDNF denatured by boiling ( $100 \mu \mathrm{g} / \mathrm{ml}, 10 \mathrm{~min}$ ) (supplemental Fig. 2, available at www.jneurosci.org as supplemental material) were entirely ineffective $(28.04 \pm 15 \mathrm{pA}, n=4, p<0.0001$; and $6.46 \pm 5.25 \mathrm{pA}, n=3, p<0.0001$, respectively). Furthermore, $I_{\mathrm{BDNF}}$ exhibited a dose-response relationship: pressure application from a pipette containing $50 \mu \mathrm{g} / \mathrm{ml}$ BDNF induced a current of $57.42 \pm 4.23 \mathrm{pA}(n=4)$, whereas a larger membrane current was elicited by $75 \mu \mathrm{g} / \mathrm{ml} \operatorname{BDNF}(178.75 \pm 48.68 \mathrm{pA} ; n=3)$ (supplemental Fig. 2, available at www.jneurosci.org as supplemental material).

The extracellular BDNF scavenger TrkB-IgG was used to estimate the effective BDNF concentration required for $I_{\mathrm{BDNF}}$ activation. TrkB-IgG is a chimeric recombinant protein that consists of the ligand-binding domain of the TrkB receptor fused to the FC domain of human IgG (to make it soluble) (Shelton et al., 1995).
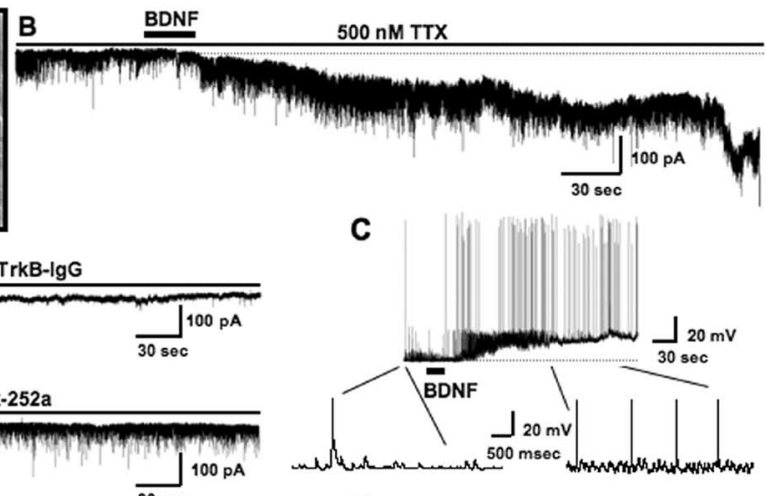

H

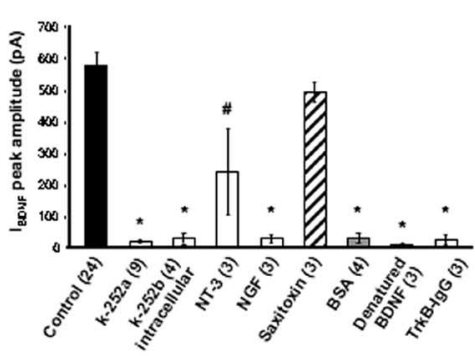

Figure 1. BDNF activation of TrkB receptors induces a slowly developing and sustained depolarizing membrane response that is not mediated by STX-sensitive $\mathrm{Na}^{+}$channels. $\boldsymbol{A}$, Representative hippocampal slice culture (from a postnatal day rat, 10 div)

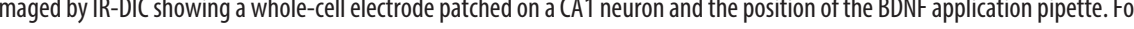
smaller amplitude than $I_{\text {BDNF }}$ (top), whereas NGF did not affect membrane conductance (bottom; both neurotrophins at 100 $\mu \mathrm{g} / \mathrm{ml}$ in the application pipette). $G$, Contrary to the fast $\mathrm{Na}^{+}$current mediated by $\mathrm{Na}_{\mathrm{v}} 1.9$ channels, $I_{\text {BDNF }}$ is insensitive to STX (10 nм). $\boldsymbol{H}$, Average amplitude of $I_{\text {BDNF }}$ in the above experimental conditions $\left({ }^{*} p<0.0001,{ }^{\#} p<0.005\right.$ vs BDNF application in TTX).

Thus, TrkB-IgG neutralizes BDNF action by effectively competing for BDNF binding to endogenous cell surface TrkB receptors, without physically interacting with or affecting these receptors. Furthermore, it displays a dose-dependent inhibition of the effects of $200 \mathrm{ng} / \mathrm{ml}$ exogenously applied BDNF and completely inhibits the effects of $200 \mathrm{ng} / \mathrm{ml} \mathrm{BDNF}$ at an equimolar $(\sim 7 \mathrm{nM})$ equivalent of TrkB-IgG $(2 \mu \mathrm{g} / \mathrm{ml})$ (McAllister et al., 1997). Bath application of $1 \mu \mathrm{g} / \mathrm{ml}$ TrkB-IgG completely prevented the BDNF-induced current after pressure ejection from a pipette containing $100 \mu \mathrm{g} / \mathrm{ml}$ BDNF (in $0.0001 \%$ BSA), even after two to three successive pulses (Fig. $1 D$ ). Because of accumulation on the slice, subsequent BDNF applications did evoke a current, albeit significantly smaller than those recorded under control conditions, suggesting that $1 \mu \mathrm{g} / \mathrm{ml}$ TrkB-IgG (i.e., $3.8 \mathrm{nM}$ ) is saturated by two to three successive BDNF applications. These results indicate that the effective BDNF concentration within the slice after a single application is $33-50 \mathrm{ng} / \mathrm{ml}$ or less; otherwise, it would have saturated the scavenger and evoked a current in response to the first application. This range of concentrations, which are equivalent to 1.2-1.8 $\mathrm{nM}$ of the BDNF dimer, are considered to specifically activate TrkB receptors. For example, TrkB-IgG concentrations between 1 and $20 \mu \mathrm{g} / \mathrm{ml}$ have been shown to prevent the induction of long-term potentiation in hippocampal slices (Figurov et al., 1996; Kang et al., 1997; Chen et al., 1999; Tyler et al., 2006), as well as BDNF-mediated increases in dendritic com- 
plexity (McAllister et al., 1997) and spine density (Tyler and Pozzo-Miller, 2001).

The requirement of Trk receptors was demonstrated by the observation that bath application of the tyrosine kinase inhibitor k-252a $\left[\left(8 R^{\star}, 9 S^{\star}, 11 S^{*}\right)-(-)\right.$-9-hydroxy-9-methoxycarbonyl-8methyl-2,3,9,10-tetrahydro-8,11-epoxy- $1 H, 8 H, 11 H$-2,7b,11atriazadibenzo(a,g)cycloocta(cde)trinden-1-one] completely prevented $I_{\mathrm{BDNF}}(17.9 \pm 4.8 \mathrm{pA} ; n=9 ; p<0.0001$ vs control) (Fig. $1 E$ ), even after three successive BDNF applications to the same cell. Moreover, inhibition of Trk receptors only in the postsynaptic cell by intracellular application of the membraneimpermeable analog k-252b (200 nM in $0.01 \%$ DMSO) also inhibited $I_{\mathrm{BDNF}}(27.58 \pm 16.51 \mathrm{pA} ; n=4 ; p<0.0001$ vs control $)$ (supplemental Fig. 2, available at www.jneurosci.org as supplemental material); the concentrations used (200 nM in $0.01 \%$ DMSO for both) are specific for receptor tyrosine kinases of the trk gene family (Knusel and Hefti, 1992). The specific role of TrkB receptors was further confirmed by applying other neurotrophins in a similar manner. NT-3 $(100 \mu \mathrm{g} / \mathrm{ml})$, which binds primarily to TrkC but also to TrkB with a lower affinity (Barbacid, 1994), induced a membrane current with similar kinetics but smaller amplitude than $I_{\mathrm{BDNF}}(238.75 \pm 138 \mathrm{pA}, n=3, p=$ 0.0122 vs control) (Fig. $1 F$ ). As expected from the low levels of TrkA expression in the postnatal hippocampus, NGF $(100 \mu \mathrm{g} /$ $\mathrm{ml})$ had only minor effects on membrane currents $(27.5 \pm 13.2$ pA; $n=3 ; p<0.0001$ vs control) (Fig. $1 F$ ). Together, activation of TrkB receptors in the postsynaptic neuron under recording is necessary for the activation of $I_{\mathrm{BDNF}}$.

It is important to note that BDNF-evoked $\mathrm{Na}^{+}$currents mediated by $\mathrm{Na}_{\mathrm{v}} 1.9$ channels have very short latencies, as well as rapid activation and inactivation kinetics (Kafitz et al., 1999), in marked contrast with the delayed, slowly activating, and longlasting $I_{\mathrm{BDNF}}$ described here in CA1 neurons and previously characterized in acutely dissociated pontine neurons (Li et al., 1999). In addition, $\mathrm{Na}_{\mathrm{v}} 1.9$-mediated currents were shown to be sensitive to the $\mathrm{Na}^{+}$channel blocker STX (Blum et al., 2002), whereas $I_{\mathrm{BDNF}}$ persisted in the presence of this toxin $(10 \mathrm{nM} ; 491.48 \pm$ $30.18 \mathrm{pA} ; n=3 ; p=0.4756$ vs control) (Fig. $1 G$ ). These differences demonstrate that two completely different mechanisms couple TrkB receptors to membrane cation conductances.

\section{$I_{\mathrm{BDNF}}$ requires both $\mathrm{IP}_{3} \mathrm{R}$-dependent $\mathrm{Ca}^{2+}$ mobilization and $\mathrm{Ca}^{2+}$ influx}

Neurotrophin-activated Trk receptors stimulate PLC $\gamma$ activity, leading to $\mathrm{IP}_{3}$ production through hydrolysis of phosphatidylinositol-4,5-bisphosphate $\left(\mathrm{PIP}_{2}\right)$ (Segal and Greenberg, 1996). The requirement of this signaling pathway for the activation of $I_{\text {BDNF }}$ was demonstrated by the complete absence of responses when BDNF was applied in the presence of the PLC inhibitor U73122 (1-[6[[(17 $\beta)$-3-methoxyestra-1,3,5(10)-triene-17-yl]amino]hexyl]-1 $H$-pyrrole-2,5-dione) (Bleasdale et al., 1990) ( $2 \mu \mathrm{M} ; 8.54 \pm 7.14 \mathrm{pA} ; n=3 ; p<0.0001$ vs control) (Fig. $2 A$ ), even after three successive BDNF applications to the same cell. Furthermore, BDNF-induced currents were significantly reduced in neurons loaded with xestospongin-C, an $\mathrm{IP}_{3} \mathrm{R}$ inhibitor (Gafni et al., 1997) (1 $\mu \mathrm{M}$ in 0.01\% DMSO; $54.06 \pm 12 \mathrm{pA} ; n=7$; $p<0.0001$ vs control) (Fig. $2 B$ ), even after three successive BDNF applications. In addition, intracellular application of heparin $(100 \mu \mathrm{g} / \mathrm{ml})$, another $\mathrm{IP}_{3} \mathrm{R}$ inhibitor (Ghosh et al., 1988), also significantly reduced $I_{\mathrm{BDNF}}$ amplitude $(37.64 \pm 15.34 \mathrm{pA}$; $n=6 ; p<0.0001$ vs control; even after four successive BDNF applications). Intriguingly, DAG produced by $\mathrm{PIP}_{2}$ hydrolysis appears to contribute to the activation of $I_{\mathrm{BDNF}}$, because the
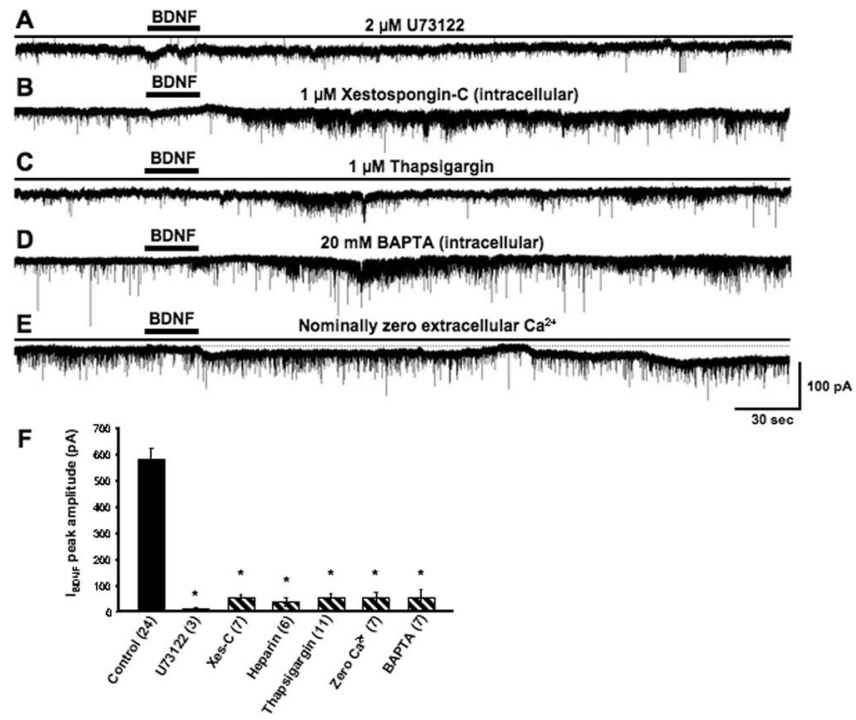

Figure 2. $I_{\mathrm{BDNF}}$ activation requires $\mathrm{PLC}$ activity, functional $\mathrm{IP}_{3}$ receptors, full intracellular stores, $\mathrm{Ca}^{2+}$ influx, and intracellular $\mathrm{Ca}^{2+}$ elevations. $\boldsymbol{A}$, Bath application of the PLC inhibitor U73122 completely blocked $I_{\text {BDNF. }}$ B, Intracellular application of xestospongin-C (Xes-C; $1 \mu \mathrm{M}$ ), a specific inhibitor of $I_{3} R s$, prevents $I_{\text {BDNF. }} C$, Depletion of intracellular stores with the SERCA pump inhibitor thapsigargin $(1 \mu \mathrm{m})$ also abolishes $I_{\mathrm{BDNF}}$. $\boldsymbol{D}$, Consistent with a requirement of $\mathrm{Ca}^{2+}$ signaling, $I_{\mathrm{BDNF}}$ was also inhibited by loading neurons with the fast $\mathrm{Ca}^{2+}$ chelator BAPTA $(20 \mathrm{~mm}) . \boldsymbol{E}$, Activation of $I_{\text {BDNF }}$ also requires extracellular $\mathrm{Ca}^{2+} . \boldsymbol{F}$, Average amplitude of $I_{\mathrm{BDNF}}$ in the above experimental conditions ( ${ }^{*} p<0.0001$ vs BDNF application in TTX).

membrane-permeable DAG analog OAG (1-oleoyl-2-acetylsn-glycerol) $(50 \mu \mathrm{M})$ also induced a membrane current, albeit smaller than $I_{\mathrm{BDNF}}$, when locally applied to CA1 pyramidal neurons $(359.82 \pm 84.66 ; n=7)$. Consistent with a requirement of $\mathrm{IP}_{3} \mathrm{R}$-dependent $\mathrm{Ca}^{2+}$ mobilization, pretreatment $(30 \mathrm{~min})$ with $1 \mu \mathrm{M}$ thapsigargin (in $0.01 \% \mathrm{DMSO}$ ), which depletes intracellular $\mathrm{Ca}^{2+}$ stores by inhibiting sarcoendoplasmic reticulum $\mathrm{Ca}^{2+}$ ATPase (SERCA) pumps (Thastrup et al., 1990), also reduced $I_{\mathrm{BDNF}}(51.59 \pm 17.97 \mathrm{pA} ; n=11 ; p<0.0001 \mathrm{vs}$ control) (Fig. $2 C$ ), even after five successive BDNF applications to the same cell. The requirement of intracellular $\mathrm{Ca}^{2+}$ elevations for $I_{\mathrm{BDNF}}$ activation was confirmed by the observation that the $\mathrm{Ca}^{2+}$ chelator BAPTA (20 $\mathrm{mM}$ in the pipette solution) significantly reduced $I_{\mathrm{BDNF}}$ $(65.13 \pm 28.95 \mathrm{pA} ; n=7 ; p<0.0001$ vs control; even after five successive BDNF applications to the same cell) (Fig. $2 D$ ). Intriguingly, $I_{\mathrm{BDNF}}$ was also significantly reduced when BDNF was applied in a nominally $\mathrm{Ca}^{2+}$-free extracellular solution (52.9 \pm 20.4 pA; $n=7 ; p<0.0001$ vs control; even after six successive BDNF applications to the same cell) (Fig. $2 E$ ), demonstrating that mobilization from intracellular $\mathrm{Ca}^{2+}$ stores and $\mathrm{Ca}^{2+}$ influx are both necessary for the activation of $I_{\mathrm{BDNF}}$. Simultaneous wholecell voltage-clamp recording and $\mathrm{Ca}^{2+}$ imaging experiments further showed that $I_{\mathrm{BDNF}}$ is both preceded and associated with elevations of intracellular $\mathrm{Ca}^{2+}$ concentration (our unpublished observation). Together, these observations demonstrate that Trk receptors, $\mathrm{IP}_{3} \mathrm{Rs}$, full intracellular $\mathrm{Ca}^{2+}$ stores, and $\mathrm{Ca}^{2+}$ influx are required for BDNF-induced membrane currents, suggesting the involvement of TRPC channels (Montell et al., 2002; Clapham, 2003).

\section{The role of TRPC channels in BDNF-induced membrane currents}

TRPC3 channel subunits colocalize and coimmunoprecipitate with TrkB receptors (Li et al., 1999). Consistent with a potential 
role of TRPC channels in $I_{\mathrm{BDNF}}$, TRPC3 localized in the cell body and dendritic processes of pyramidal-like hippocampal neurons in primary culture, as well as in neuronal cell bodies and dendritic processes of the CA1 region of cultured slices (Fig. $3 A$ ). Furthermore, $I_{\mathrm{BDNF}}$ in pontine neurons was shown to be mediated by channels containing TRPC3 subunits ( $\mathrm{Li}$ et al., 1999). Consistently, $I_{\mathrm{BDNF}}$ in CA1 neurons was prevented by SKF-96365 [1-[ $\beta$-3-(4-methoxyphenyl)propoxy]-4-methoxyphenethyl]- $1 \mathrm{H}$-imidazole hydrochloride] (30 $\mu \mathrm{M}$ in $0.01 \%$ DMSO; $18.39 \pm 10.16 \mathrm{pA} ; n=7 ; p<$ 0.0001 vs control; even after five BDNF applications) (Fig. 3B), an inhibitor of storeoperated $\mathrm{Ca}^{2+}$ entry (SOC) in several cell types (e.g., human neutrophils, platelets and endothelial cells, HL-60 cells, rat thymic lymphocytes, and thyroid FRTL-5 cells) (Merritt et al., 1990), as well as in cells heterologously expressing TRPC3 channels (Zhu et al., 1998). It was originally reported that SKF-96365 also inhibited voltage-gated $\mathrm{Ca}^{2+}$ channels in $\mathrm{GH} 3$ pituitary cells and rabbit ear-artery smooth muscle cells (Merritt et al., 1990); however, a broad-spectrum $\mathrm{Ca}^{2+}$ channel blocker (i.e., $200 \mu \mathrm{M} \mathrm{Cd}^{2+}$ ) did not affect $I_{\mathrm{BDNF}}$ in CA1 pyramidal neurons in our experiments (see above and supplemental Fig. 1, available at www.jneurosci.org as supplemental material). Introducing antibodies against intracellular domains of TRPC subunits through the whole-cell pipette has been shown to inhibit TRPC-like membrane conductances activated by BDNF (Li et al., 1999) and mGluR1/5 agonists (Kim et al., 2003; Faber et al., 2006). After $45 \mathrm{~min}$ of whole-cell access, anti-TRPC3 antibodies (1:100 dilution in the pipette solution) prevented $I_{\mathrm{BDNF}}$ in CA1 neurons (26.51 $\pm 15 \mathrm{pA} ; n=6 ; p<0.0001$ vs control) (Fig. $4 C$ ). Conversely, anti-TRPC5 antibodies $(1: 100)$ had no effect on $I_{\mathrm{BDNF}}(479.04 \pm 208.75 \mathrm{pA} ; n=3 ; p=0.4697$ vs control; $45 \mathrm{~min}$ of whole-cell access) (Fig. $4 C$ ), indicating that the effects of antiTRPC3 on $I_{\text {BDNF }}$ were specific.

To directly demonstrate the requirement of TRPC3 channel subunits for the activation of $I_{\mathrm{BDNF}}$, we knocked down their expression using specific siRNA oligonucleotides. The expression levels of TRPC3 were significantly reduced in TRPC3 siRNAtransfected cultured hippocampal neurons, as demonstrated by Western blotting (Fig. 4A). Slice cultures were then biolistically transfected with gold particles coated with siRNA oligos and cDNA plasmids encoding for eYFP for cell identification purposes. After $48 \mathrm{~h}$ of transfection, eYFP-transfected CA1 pyramidal neurons were identified under fluorescence microscopy (Fig. $4 B$ ) and subjected to whole-cell recording following our standard procedures (Alonso et al., 2004). Gene-gun transfection of this TRPC3 siRNA construct completely prevented the activation of $I_{\mathrm{BDNF}}(42.89 \pm 20.96 \mathrm{pA} ; n=4 ; p<0.05$ vs control) (Fig. $4 C$ ), whereas transfecting eYFP or a random siRNA construct did not affect BDNF-induced currents $(456.41 \pm 220.44 \mathrm{pA} ; n=3 ; p>$ 0.05 vs control) (Fig. $4 C$ ). Together, these results demonstrate that $I_{\mathrm{BDNF}}$ in CA1 neurons is mediated by nonselective cationic channels containing TRPC3 subunits.

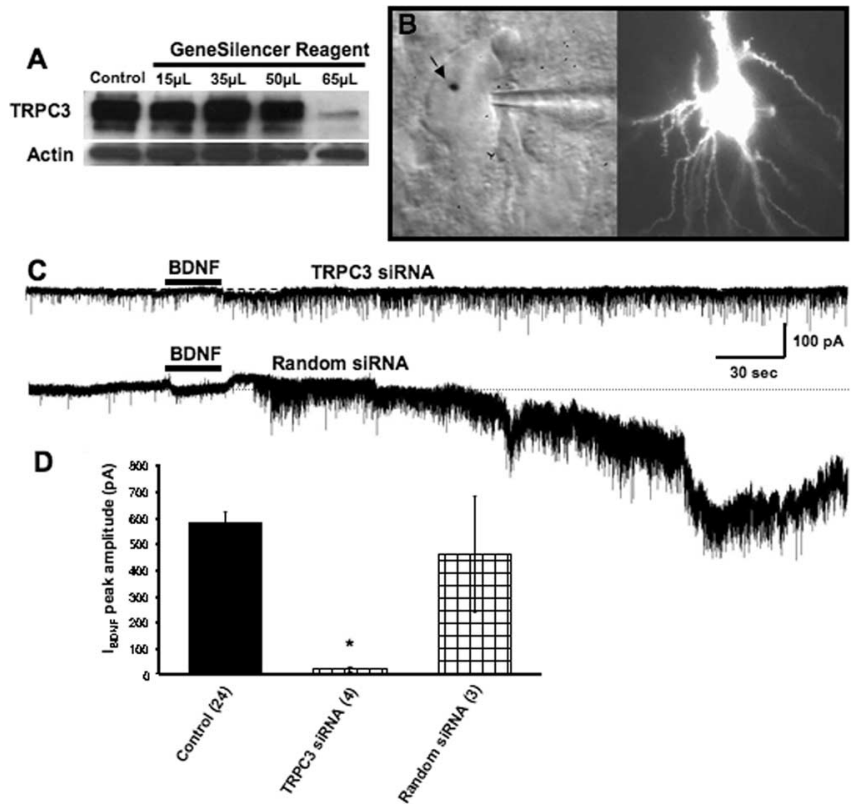

Figure 4. TRPC3 subunits are necessary for the activation of $I_{\mathrm{BDNF}}$. $\boldsymbol{A}$, siRNA designed to knockdown TRPC3 expression reduced TRPC3 protein levels in primary cultured neurons. $\boldsymbol{B}$, IR-DIC image (left) and eYFP fluorescence ( $488 \mathrm{~nm}$ excitation) of a CA1 pyramidal neuron biolistically transfected with siRNA oligos and eYFP CDNA. Note the gold particle (arrow) on the nucleus of the neuron and the whole-cell patch pipette toward its right. C, BDNF failed to induce a membrane current in CA1 pyramidal neurons transfected with TRPC3 siRNA (top), whereas biolistic transfection with random siRNA oligos and eYFP CDNA does not affect $I_{\text {BDNF }}$ amplitude or activation kinetics. $D$, Average amplitude of $I_{B D N F}$ in the above experimental conditions $\left({ }^{*} p<0.0001\right.$ vs BDNF application in TTX)

\section{BDNF increases the surface expression of TRPC 3 in hippocampal neurons}

It has been shown recently that TRPC5 subunits are rapidly translocated to the plasma membrane by growth factor stimulation of PI3 kinase, a mechanism required for the activation of TRPC5 currents in HEK293 cells (Bezzerides et al., 2004). Consistent 


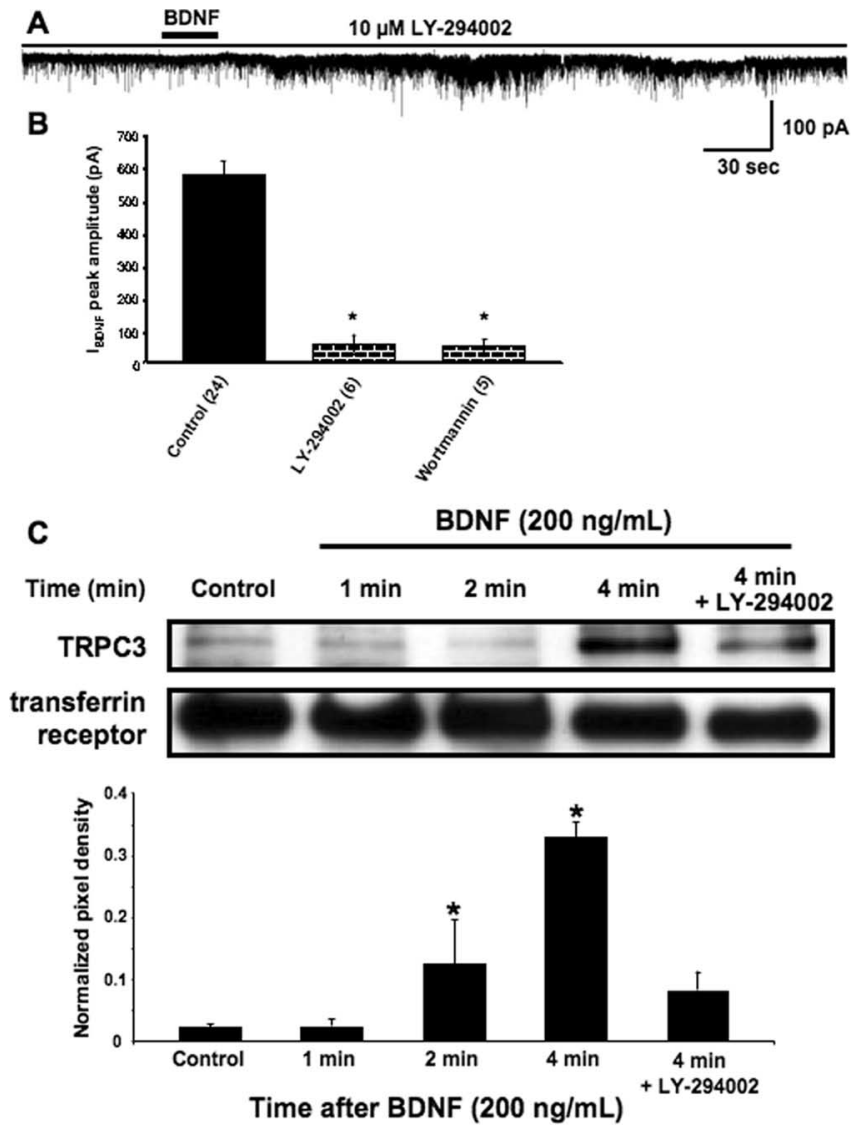

Figure 5. $\mathrm{PI} 3$ kinase signaling is required for $I_{\mathrm{BDNF}}$ and the rapid increase in TRPC3 surface content. $\boldsymbol{A}, I_{\mathrm{BDNF}}$ was reduced by the PI3 kinase inhibitor LY-294002 (10 $\left.\mu \mathrm{M}\right)$. B, Average amplitude of $I_{\text {BDNF }}$ in the above experimental conditions $\left({ }^{*} p<0.0001\right.$ vs BDNF application in TTX). C, Surface biotinylation reactions on cultured hippocampal neurons revealed that levels of surface accessible TRPC3 progressively increased after BDNF application with a time course that parallels the time course of $I_{\text {BDNF }}$ activation (1, 2, and 4 min). In addition, the same PI3 kinase

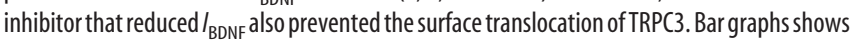
the quantitative analysis of surface biotinylation reactions, using the transferrin receptor for normalization of pixel intensity.

with this model, $I_{\mathrm{BDNF}}$ in CA1 neurons was reduced by the PI3 kinase inhibitor LY-294002 [2-(4-morpholinyl)-8-phenyl1(4H)-benzopyran-4-one hydrochloride] (Vlahos et al., 1994) (10 $\mu \mathrm{M}$ in $0.01 \%$ DMSO; $58.13 \pm 29.12 \mathrm{pA} ; n=6 ; p<0.0001 \mathrm{vs}$ control) (Fig. 5A), even after two BDNF applications. Wortmannin (100 nM in $0.01 \%$ DMSO), another PI3 kinase inhibitor, also prevented $I_{\mathrm{BDNF}}(52.37 \pm 20.94 \mathrm{pA} ; n=5 ; p<0.001$ vs control $)$ (Fig. $5 B$ ), even after three BDNF applications.

To test the possibility that the sustained kinetics of $I_{\mathrm{BDNF}}$ reflect membrane insertion of TRPC subunits, we performed surface biotinylation reactions on cultured hippocampal neurons using the transferrin receptor as a surface protein loading control. Indeed, levels of surface-accessible TRPC3 progressively increased after BDNF application with a time course that parallels the time course of $I_{\mathrm{BDNF}}$ activation (Fig. $5 C$ ). The pixel intensity of TRPC3 bands, normalized to the transferrin receptor, increased from a baseline level of $0.02 \pm 0.01$ to $0.13 \pm 0.07$ after $2 \mathrm{~min}$ and to $0.33 \pm 0.02$ after 4 min of BDNF exposure $(n=3 ; p<0.05$ vs baseline). In addition, the same PI3 kinase inhibitor that reduced $I_{\text {BDNF }}(\mathrm{LY}-294002,10 \mu \mathrm{M})$ also prevented the surface translocation of TRPC3 (0.08 $\pm 0.03 ; n=3 ; p>0.05$ vs baseline) (Fig. $5 C$ ), suggesting that $\mathrm{BDNF} / \mathrm{TrkB}$ signaling triggers rapid vesicular insertion of TRPC channels leading to a sustained membrane current.
Activation of TRPC-like currents by endogenously released native BDNF during patterned afferent stimulation

The most effective stimulation to release endogenous native BDNF from cultured hippocampal cells is TBS (Balkowiec and Katz, 2002). Consistently, TBS of afferent fibers within CA1 stratum radiatum in the presence of antagonists of AMPA, NMDA, mGluR1/5, and $\mathrm{GABA}_{\mathrm{A}}$ receptors evoked inward currents in CA1 pyramidal neurons voltage clamped at a holding potential of -65 $\mathrm{mV}(20 \mu \mathrm{M}$ GYKI-52466 or $20 \mu \mathrm{M}$ CNQX; $20 \mu \mathrm{M}$ MK-801 or 50 $\mu \mathrm{M}$ D,L-APV; $100 \mu \mathrm{M}$ LY-367385; $50 \mu \mathrm{M}$ picrotoxin; $10 \mathrm{nM}$ TTX to reduce polysynaptic activity; and Cs-gluconate patch solutions to block $\mathrm{GABA}_{\mathrm{B}}$-coupled $\mathrm{K}^{+}$channels). The postsynaptic currents recorded under these conditions developed slowly and outlasted the five bursts of the TBS (Fig. $6 A-C$, arrows), had a mean amplitude of $40.62 \pm 3.83 \mathrm{pA}(n=18)$, and returned to baseline after $\sim 2 \mathrm{~s}$ from the start of theta burst stimulation. These responses were highly stable during baseline acquisition times ranging from 10 to $65 \mathrm{~min}$. The coefficient of variance of these baseline responses was 0.20 (range of $0.04-0.38 ; n=18$ ), and they lack a significant "rundown." Differences in amplitude and duration between exogenously applied BDNF and these responses to afferent stimulation likely reflect a more limited amount of endogenous BDNF for release and/or a highly localized site of BDNF release activating a small number of TrkB receptors. Similar differences are well known to exist between focal application of mGluR agonists and synaptically mediated mGluR responses. The BDNF scavenger TrkB-IgG $(1 \mu \mathrm{g} / \mathrm{ml}$, equivalent to $3.8 \mathrm{nM}$ of the receptor dimer) significantly reduced the amplitude of these slow membrane currents $(14.04 \pm 2.9$ vs $35.52 \pm 3.7$ pA; $n=5 ; p=0.0013$ ) (Fig. 6A). In addition, slow TBS-induced currents were significantly inhibited by the Trk receptor inhibitor $\mathrm{k}-252 \mathrm{a}(200 \mathrm{~nm} ; 10.1 \pm 0.9$ vs $23.78 \pm 1.4 \mathrm{pA} ; n=5 ; p=0.0005)$ (Fig. 6B). Last, the TRPC channel inhibitor SKF-96365 (30 $\mu \mathrm{M})$ also reduced these slow membrane responses $(11.42 \pm 1.9$ vs $38.96 \pm 9.2 \mathrm{pA} ; n=5 ; p=0.0127$ ) (Fig. 6C). These results strongly suggest that stimulation of afferent fibers within CA1 stratum radiatum is able to release endogenous BDNF, which in turn stimulates Trk receptors, activating a TRPC-dependent slow membrane current in CA1 pyramidal neurons reminiscent of $I_{\mathrm{BDNF}}$, the membrane current activated by brief pulses of exogenously applied BDNF.

TRPC3 channels are necessary for BDNF to increase dendritic spine density

We have shown previously that BDNF increases dendritic spine density in CA1 pyramidal neurons of hippocampal slice cultures through the activation of Trk receptors and the mitogenactivated protein kinase/ERK signaling pathway (Tyler and Pozzo-Miller, 2001; Alonso et al., 2004). Changes in the structure of dendritic spines, such as their formation, elimination, or variations in morphology, are thought to depend on the dynamics of the actin cytoskeleton, whereas proteins affecting actin cytoskeleton dynamics are sensitive to changes in $\mathrm{Ca}^{2+}$ concentrations (Yuste and Bonhoeffer, 2001). Considering the sustained membrane depolarization (Fig. $1 C$ ), the increase in cytoplasmic $\mathrm{Ca}^{2+}$ concentration during activation of $I_{\mathrm{BDNF}}$ in CA1 neurons (our unpublished observation) and that ERK1/2 activation is $\mathrm{Ca}^{2+}$ sensitive (Agell et al., 2002), we hypothesized that the BDNFinduced increase in dendritic spine density requires functional TRPC channels. BDNF (250 ng/ml; $24 \mathrm{~h})$ significantly increased dendritic spine density in eYFP-transfected CA1 pyramidal neurons $(9.32 \pm 0.85$ spines $/ 10 \mu \mathrm{m}$ dendrite, $n=16$ cells from 10 slices vs $15.84 \pm 2.02$ spines $/ 10 \mu \mathrm{m}, n=3$ cells from 3 slices; $p<$ 
0.01 ANOVA, followed by Newman-Keuls multiple comparison test) (Fig. 7A,B). Consistent with a role of TRPC channels in BDNF-induced spine formation, the inhibitor SKF-96365 (30 $\mu \mathrm{M})$ prevented the neurotrophin effect on spine density (SKF-96365 plus BDNF, $10.56 \pm 1.17$ spines $/ 10 \mu \mathrm{m}, n=6$ cells from 4 slices vs SKF-96365, $9.95 \pm 0.94$ spines/10 $\mu \mathrm{m}$, $n=10$ cells from 8 slices; $p>0.05$ ) (Fig. $7 A, B)$. Likewise, 2-aminoethoxydiphenyl borate (2-APB) $(100 \mu \mathrm{M})$, another inhibitor of TRPC channels, prevented the increase in spine density caused by BDNF (2-APB plus BDNF, $4.15 \pm 0.34$ spines $/ 10 \mu \mathrm{m}, n=5$ cells from 6 slices vs 2 -APB, $4.69 \pm 0.45$ spines $/ 10 \mu \mathrm{m}, n=7$ cells from 5 slices; $p>0.05$ ) (Fig. $7 A, B$ ). The significant reduction in spine density observed after incubation with 2-APB alone compared with untreated control neurons $(p<0.001)$ may reflect its effect on $\mathrm{IP}_{3} \mathrm{Rs}$ and the potential role of intracellular $\mathrm{Ca}^{2+}$ stores on spine morphology and/or maintenance (Harris, 1999; Korkotian and Segal, 1999).

To directly implicate TRPC3 channels in these effects, we cotransfected hippocampal slices with the same siRNA oligonucleotides that reduced TRPC3 expression and abolished the activation of $I_{\mathrm{BDNF}}$ (Fig. 4), along with eYFP to visualize dendritic morphology. Indeed, BDNF failed to increase spine density in CA1 pyramidal neurons transfected with TRPC3 siRNA (TRPC3 siRNA, $11.89 \pm 0.32$ spines $/ 10 \mu \mathrm{m}$, $n=4$ cells from 4 slices vs TRPC3 siRNA plus BDNF, $8.27 \pm$ 0.6 spines $/ 10 \mu \mathrm{m}, n=12$ cells from 11 slices; $p>0.05$, ANOVA followed by Newman-Keuls multiple comparison test) (Fig. $7 A, B$ ). It is important to note that TRPC3 siRNA oligonucleotides did not affect spine density compared with serum-free controls $(p>0.05)$. Quantitative spine density data are summarized in supplemental Table 1 (available at www.jneurosci.org as supplemental material). These observations directly demonstrate that TRPC3 channels, which mediate $I_{\mathrm{BDNF}}$, are required for BDNF to increase spine density in CA1 pyramidal neurons. Together, these results support a significant physiological role for the BDNF-induced postsynaptic current mediated by TRPC3 channels, namely the formation of dendritic spines.

\section{Discussion}

The present study provides four novel insights into the immediate actions of BDNF on hippocampal neurons in addition to a direct consequence of those effects for neurotrophin-initiated dendritic remodeling of pyramidal neurons. First, CA1 pyramidal neurons express $I_{\mathrm{BDNF}}$, a sustained nonselective cationic current that is evoked by BDNF stimulation of postsynaptic TrkB receptors leading to the activation of TRPC3-containing ion channels. Second, BDNF evokes rapid membrane insertion of TRPC3 subunits in hippocampal neurons, with a time course that parallels $I_{\mathrm{BDNF}}$ activation. Third, afferent theta burst stimulation in the absence of glutamatergic and GABAergic transmission revealed slow membrane currents that are sensitive to the BDNF scavenger TrkB-IgG, as well as to Trk and TRPC inhibitors, re- sembling the pharmacological profile of the exogenous BDNFactivated membrane conductance. Last, siRNA-mediated TRPC3 knockdown and TRPC inhibitors prevented the increase in spine density by BDNF, providing evidence of an intriguing consequence for the activation of sustained membrane depolarizations associated with intracellular $\mathrm{Ca}^{2+}$ elevations. The steps in the BDNF-initiated signaling cascade leading to the activation of TRPC3-mediated membrane currents are summarized in the model shown in Figure 8.

$I_{\mathrm{BDNF}}$ in CA1 neurons is prevented by bath application of tyrosine kinase inhibitors, such as k-252a and k-252b. NT-3, which binds primarily to TrkC but also to TrkB with a lower affinity (Barbacid, 1994), induces a membrane current with similar kinetics but smaller amplitude than $I_{\mathrm{BDNF}}$, whereas NGF evokes only minor changes in membrane current. Consistent with the stimulation of PLC $\gamma$ by TrkB, $I_{\mathrm{BDNF}}$ is sensitive to the inhibition of PLC by $\mathrm{U} 73122$ and of $\mathrm{IP}_{3} \mathrm{Rs}$ by xestospongin- $\mathrm{C}$ and heparin. Depletion of intracellular $\mathrm{Ca}^{2+}$ stores with thapsigargin also inhibited $I_{\mathrm{BDNF}}$, as did the removal of extracellular $\mathrm{Ca}^{2+}$. Together with the sensitivity to intracellular $\mathrm{Ca}^{2+}$ buffering with BAPTA and the concurrent $\mathrm{Ca}^{2+}$ elevations, these results demonstrate the critical requirement of TrkB-initiated $\mathrm{Ca}^{2+}$-dependent signaling in the activation of $I_{\mathrm{BDNF}}$.

It has been known that BDNF elicits somatic $\mathrm{Ca}^{2+}$ elevations in cultured hippocampal neurons (Berninger et al., 1993), but the mechanisms remain unclear. These somatic $\mathrm{Ca}^{2+}$ elevations in cultured neurons were reduced, but not completely blocked, in the absence of extracellular $\mathrm{Ca}^{2+}$ (Finkbeiner et al., 1997; Li et al., 1998), suggesting that both $\mathrm{Ca}^{2+}$ influx and mobilization contribute to the responses. Thus, BDNF may evoke capacitative $\mathrm{Ca}^{2+}$ entry (Putney, 2003), a mechanism postulated to be mediated by some members of the TRPC channel subfamily (Birnbaumer et al., 1996; Mikoshiba, 1997; Montell et al., 2002) (but 

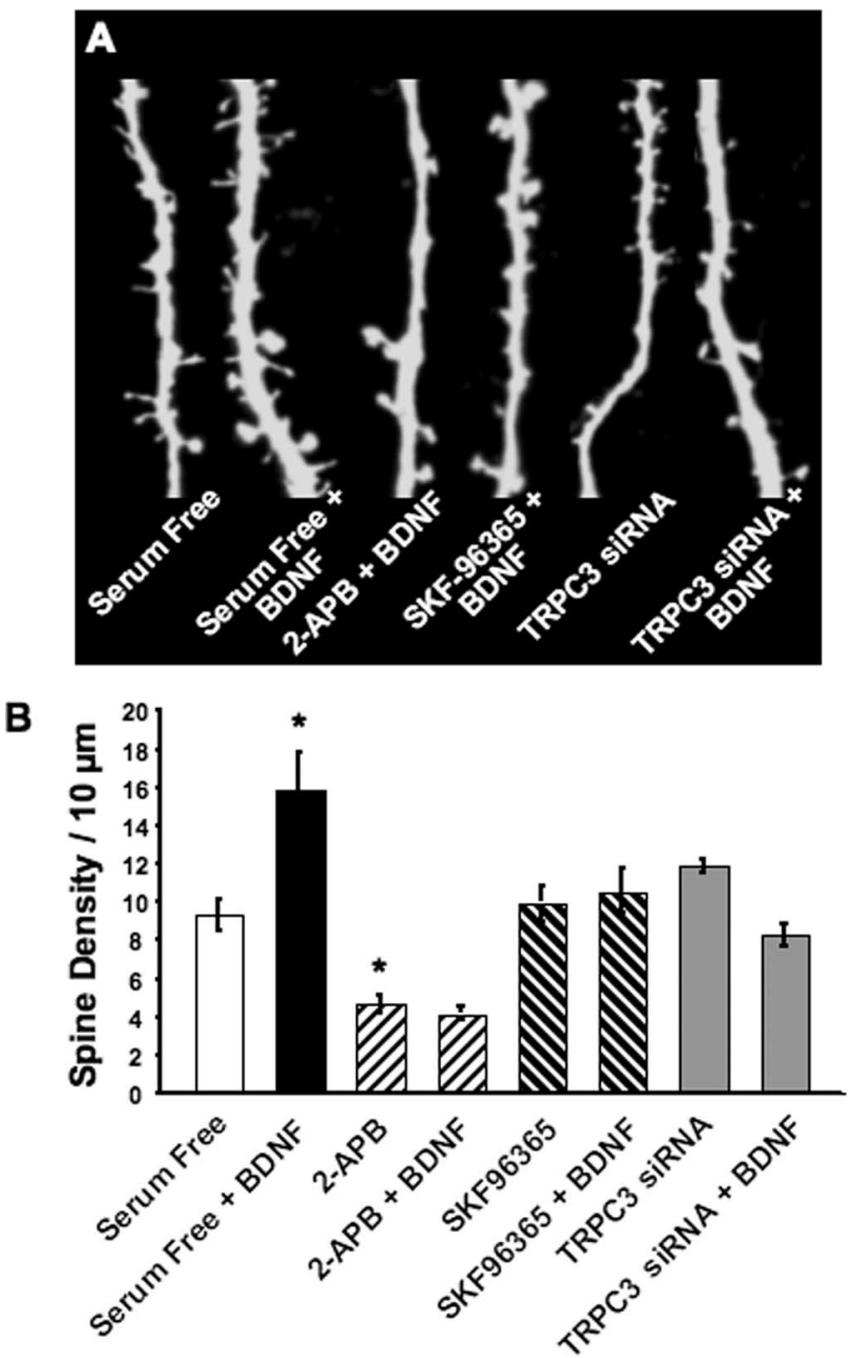

Figure 7. Functional TRPC3 channels are required for BDNF to increase dendritic spine density in CA1 pyramidal neurons. Slice cultures were transfected with either eYFP CDNA alone or in combination with TRPC3 siRNA oligonucleotides. Slices were exposed to BDNF ( $200 \mathrm{ng} / \mathrm{ml}$ in serum-free media) for $24 \mathrm{~h}$, and spine density was measured by confocal microscopy $24 \mathrm{~h}$ after transfection. $A$, Representative examples of segments of apical secondary and tertiary dendritic branches of eYFP-transfected CA1 pyramidal neurons. The TRPC inhibitors SKF-96365 and 2-APB prevented the increase in spine density by BDNF. Likewise, siRNA-mediated knockdown of TRPC 3 abolished the effect of BDNF on spine formation, without effects of its own. $B$, Average spine density in the above mentioned experimental groups. ${ }^{*} p<0.05$ compared with serumfree controls, as per ANOVA followed by Newman-Keuls multiple comparison post hoc test.

see Clapham, 2003). Indeed, TRPC3/6 channels mediate BDNFevoked $\mathrm{Ca}^{2+}$ signals in growth cones of cultured cerebellar granule cells ( $\mathrm{Li}$ et al., 2005), whereas XTRPC1, a Xenopus homolog of TRPC1, plays a similar role in BDNF-induced growth cone turning in vitro (Wang and Poo, 2005). Consistently, siRNAmediated TRPC3 knockdown, or intracellular application of anti-TRPC3 antibodies, but not anti-TRPC5, prevented the activation of $I_{\mathrm{BDNF}}$ in CA1 neurons. Thus, our results suggest that $I_{\mathrm{BDNF}}$ is mediated by ion channels containing at least TRPC3 subunits.

Additional support for the role of TRPC channels in these responses comes from the BDNF-induced increase of surface accessible TRPC3 subunits after a time course that parallels $I_{\mathrm{BDNF}}$ activation. The intriguing mechanism of rapid vesicular insertion of TRPC channels to the plasma membrane has been shown to mediate homomeric TRPC5 currents and hippocampal cell neu- rite extension stimulated by epidermal growth factor (Bezzerides et al., 2004). Similarly, PLC $\beta$-coupled muscarinic receptors cause membrane insertion of TRPC6 (Cayouette et al., 2004) and of TRPC3 (Singh et al., 2004) (but see Smyth et al., 2006) in HEK293 cells. We show here that $I_{\mathrm{BDNF}}$ and the increase in TRPC3 surface content in hippocampal neurons are both sensitive to a PI3 kinase inhibitor, as reported for TRPC5 membrane translocation (Bezzerides et al., 2004). Thus, membrane delivery of TRPC3 subunits may contribute to sustained BDNF-induced membrane currents in hippocampal neurons.

\section{Physiological relevance and potential function of $I_{\mathrm{BDNF}}$}

Nonselective cationic currents resembling TRPC currents have been described in cortical and hippocampal neurons (Alzheimer, 1994; Haj-Dahmane and Andrade, 1996; Congar et al., 1997). Recent evidence indicates that TRPC1-containing channels mediate cation currents activated by the selective group I mGluR agonist $(R S)$-3,5-dihydroxyphenylglycine (DHPG) in Purkinje neurons (Kim et al., 2003). Similar DHPG-evoked currents sensitive to TRPC inhibitors were also recorded in hippocampal pyramidal neurons (Gee et al., 2003; Rae and Irving, 2004) and midbrain dopamine neurons (Tozzi et al., 2003). Consistently, we found that the group I mGluR agonist DHPG evoked $\mathrm{Ca}^{2+}$ signals in CA1 neurons that preceded a slow inward current (data not shown), resembling BDNFinduced dendritic $\mathrm{Ca}^{2+}$ elevations associated with $I_{\mathrm{BDNF}}$ (our unpublished observation). Thus, TRPC channels are mediators of the slow membrane responses initiated by mGluRs and neurotrophin receptors coupled to PLC-dependent signaling cascades.

It is worth noting that $I_{\mathrm{BDNF}}$ recorded in pontine and CA1 neurons is markedly different from the much faster and transient TTX-insensitive $\mathrm{Na}^{+}$current activated by TrkB ligands in several regions of the brain (Kafitz et al., 1999). In addition, the BDNF-activated $\mathrm{Na}^{+}$current is blocked by the $\mathrm{Na}^{+}$channel blocker saxitoxin (Blum et al., 2002), whereas $I_{\mathrm{BDNF}}$ in CA1 neurons is not (Fig. 1G). BDNF, like classical neuropeptides, is synthesized and packaged in dense-core vesicles for their delivery to dendrites and axons, in which it is slowly released by large $\mathrm{Ca}^{2+}$ elevations evoked by high-frequency spike trains (Lessmann et al., 2003; Brigadski et al., 2005). Indeed, BDNF is most effectively released from hippocampal neurons by TBS (Balkowiec and Katz, 2002). Consistent with this mode of slow release, we present here the first direct evidence of a membrane response to endogenously released BDNF. After blockade of glutamatergic and GABAergic ionotropic and metabotropic receptors, afferent fiber stimulation using a TBS pattern evoked a slowly developing inward current in CA1 neurons. Membrane inward currents outlasted the TBS train and were sensitive to the extracellular BDNF scavenger TrkB-IgG, as well as to Trk receptor and TRPC/SOC channel inhibitors, thus resembling the membrane currents induced by exogenously applied BDNF. In addition, these responses represent one of a handful of observations of activation of TRPC channels by afferent fiber stimulation. Membrane currents mediated by TRPC channels activated by group I mGluRs in response to endogenously released glutamate have been observed in Purkinje cells (Kim et al., 2003), dopamine neurons of the substantia nigra compacta (Bengtson et al., 2004), and neurons in the lateral amygdala (Faber et al., 2006). We propose that a slow membrane current, such as $I_{\mathrm{BDNF}}$, intricately linked with parallel presynaptic actions will have a longlasting impact on neuronal function. 


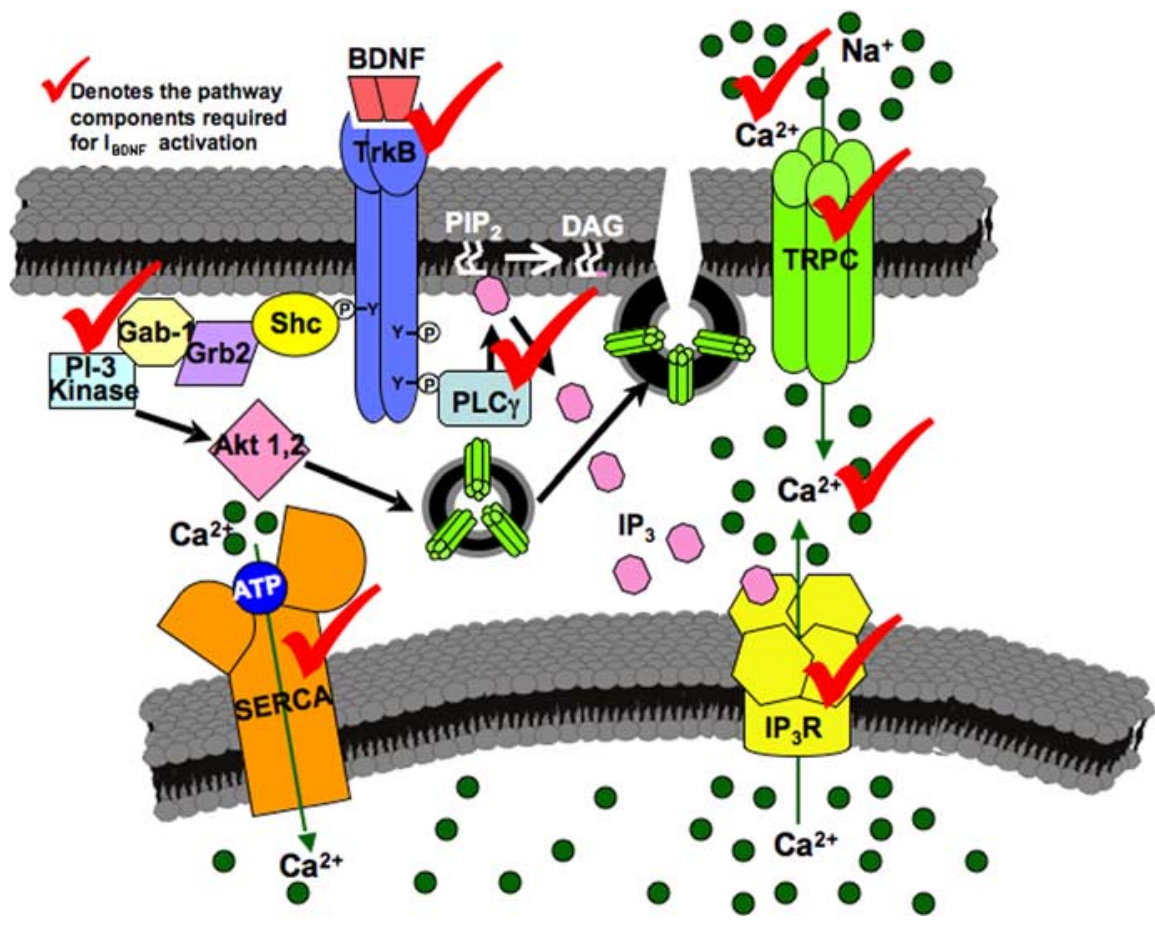

Figure 8. Schematic representation of the proposed model for intracellular signaling cascades initiated by BDNF stimulation of TrkB receptors leading to the activation of membrane currents and $\mathrm{Ca}^{2+}$ signals mediated by TRPC3-containing channels. Gab-1, Growth-associated binder 1; Grb2, growth factor receptor-bound protein 2; Shc, Srchomology 2 domain-containing transforming protein $C 1 ; P$, phosphate groups; $Y$, tyrosine residues.

What is the role of BDNF-induced membrane currents? We have shown previously that BDNF increases spine density in CA1 neurons (Tyler and Pozzo-Miller, 2001; Alonso et al., 2004), and, combined with miniature synaptic transmission, it increases the proportion of a particular spine type, stubby type I spines (Tyler and Pozzo-Miller, 2003). However, a specific mechanism by which BDNF modulates dendritic structure in CA1 neurons has not yet been identified. Our observations demonstrate that siRNA-mediated TRPC3 knockdown as well as TRPC inhibitors prevented the increase in spine density by BDNF. In this context, a long-lasting membrane depolarization associated with sustained intracellular $\mathrm{Ca}^{2+}$ elevations such as those induced by brief BDNF applications seems particularly suited to trigger the cytoskeletal rearrangements necessary for spine remodeling and/or formation, a characteristic consequence of BDNF signaling. Similarly, $\mathrm{Ca}^{2+}$ mobilization from intracellular stores (Korkotian and Segal, 1999) and activation of group I mGluRs (Vanderklish and Edelman, 2002) induce changes in spine form and promote spine formation. The similarities of mGluR and TrkB signaling suggest that the convergence of these pathways on TRPC channels may trigger a program of spine formation and/or maturation via $\mathrm{Ca}^{2+}$. dependent, actin-based structural remodeling. In this view, TRPC channels emerge as novel effectors of BDNF-mediated dendritic remodeling through the activation of a sustained depolarization associated with intracellular $\mathrm{Ca}^{2+}$ elevations.

\section{References}

Agell N, Bachs O, Rocamora N, Villalonga P (2002) Modulation of the Ras/Raf/MEK/ERK pathway by $\mathrm{Ca}^{2+}$, and calmodulin. Cell Signal 14:649-654.

Alonso M, Medina JH, Pozzo-Miller L (2004) ERK1/2 activation is necessary for BDNF to increase dendritic spine density in hippocampal CA1 pyramidal neurons. Learn Mem 11:172-178.
Alzheimer C (1994) A novel voltage-dependent cation current in rat neocortical neurones. J Physiol (Lond) 479:199-205.

Amaral MD, Chapleau CA, Pozzo-Miller L (2007) Transient receptor potential channels as novel effectors of brain-derived neurotrophic factor signaling: potential implications for Rett syndrome. Pharmacol Ther 113:394-409.

Balkowiec A, Katz DM (2002) Cellular mechanisms regulating activity-dependent release of native brain-derived neurotrophic factor from hippocampal neurons. J Neurosci 22:10399-10407.

Barbacid M (1994) The Trk family of neurotrophin receptors. J Neurobiol 25:1386-1403.

Bengtson CP, Tozzi A, Bernardi G, Mercuri NB (2004) Transient receptor potential-like channels mediate metabotropic glutamate receptor EPSCs in rat dopamine neurones. J Physiol (Lond) 555:323-330.

Berninger B, Garcia DE, Inagaki N, Hahnel C, Lindholm D (1993) BDNF and NT-3 induce intracellular $\mathrm{Ca}^{2+}$ elevation in hippocampal neurones. NeuroReport 4:1303-1306.

Bezzerides VJ, Ramsey IS, Kotecha S, Greka A, Clapham DE (2004) Rapid vesicular translocation and insertion of TRP channels. Nat Cell Biol 6:709-720.

Birnbaumer L, Zhu X, Jiang M, Boulay G, Peyton M, Vannier B, Brown D, Platano D, Sadeghi H, Stefani E, Birnbaumer M (1996) On the molecular basis and regulation of cellular capacitative calcium entry: roles for $\operatorname{Trp}$ proteins. Proc Natl Acad Sci USA 93:15195-15202.

Bleasdale JE, Thakur NR, Gremban RS, Bundy GL, Fitzpatrick FA, Smith RJ, Bunting S (1990) Selective inhibition of receptor-coupled phospholipase $\mathrm{C}$-dependent processes in human platelets and polymorphonuclear neutrophils. J Pharmacol Exp Ther 255:756-768.

Blum R, Kafitz KW, Konnerth A (2002) Neurotrophin-evoked depolarization requires the sodium channel $\mathrm{Na}_{\mathrm{V}} 1.9$. Nature 419:687-693.

Brigadski T, Hartmann M, Lessmann V (2005) Differential vesicular targeting and time course of synaptic secretion of the mammalian neurotrophins. J Neurosci 25:7601-7614.

Cayouette S, Lussier MP, Mathieu EL, Bousquet SM, Boulay G (2004) Exocytotic insertion of TRPC6 channel into the plasma membrane upon Gq protein-coupled receptor activation. J Biol Chem 279:7241-7246.

Chen G, Kolbeck R, Barde YA, Bonhoeffer T, Kossel A (1999) Relative contribution of endogenous neurotrophins in hippocampal long- term potentiation. J Neurosci 19:7983-7990.

Clapham DE (2003) TRP channels as cellular sensors. Nature 426:517-524.

Congar P, Leinekugel X, Ben-Ari Y, Crepel V (1997) A long-lasting calciumactivated nonselective cationic current is generated by synaptic stimulation or exogenous activation of group I metabotropic glutamate receptors in CA1 pyramidal neurons. J Neurosci 17:5366-5379.

Faber ES, Sedlak P, Vidovic M, Sah P (2006) Synaptic activation of transient receptor potential channels by metabotropic glutamate receptors in the lateral amygdala. Neuroscience 137:781-794.

Figurov A, Pozzo-Miller LD, Olafsson P, Wang T, Lu B (1996) Regulation of synaptic responses to high-frequency stimulation and LTP by neurotrophins in the hippocampus. Nature 381:706-709.

Finkbeiner S, Tavazoie SF, Maloratsky A, Jacobs KM, Harris KM, Greenberg ME (1997) CREB: a major mediator of neuronal neurotrophin responses. Neuron 19:1031-1047.

Gafni J, Munsch JA, Lam TH, Catlin MC, Costa LG, Molinski TF, Pessah IN (1997) Xestospongins: potent membrane permeable blockers of the inositol 1,4,5-trisphosphate receptor. Neuron 19:723-733.

Gahwiler BH (1981) Organotypic monolayer cultures of nervous tissue. J Neurosci Methods 4:329-342.

Gee CE, Benquet P, Gerber U (2003) Group I metabotropic glutamate re- 
ceptors activate a calcium-sensitive transient receptor potential-like conductance in rat hippocampus. J Physiol (Lond) 546:655-664.

Ghosh TK, Eis PS, Mullaney JM, Ebert CL, Gill DL (1988) Competitive, reversible, and potent antagonism of inositol 1,4,5-trisphosphateactivated calcium release by heparin. J Biol Chem 263:11075-11079.

Haj-Dahmane S, Andrade R (1996) Muscarinic activation of a voltagedependent cation nonselective current in rat association cortex. J Neurosci 16:3848-3861.

Harris KM (1999) Calcium from internal stores modifies dendritic spine shape. Proc Natl Acad Sci USA 96:12213-12215.

Kafitz KW, Rose CR, Thoenen H, Konnerth A (1999) Neurotrophin-evoked rapid excitation through TrkB receptors. Nature 401:918-921.

Kang H, Welcher AA, Shelton D, Schuman EM (1997) Neurotrophins and time: different roles for TrkB signaling in hippocampal long-term potentiation. Neuron 19:653-664.

Kim SJ, Kim YS, Yuan JP, Petralia RS, Worley PF, Linden DJ (2003) Activation of the TRPC1 cation channel by metabotropic glutamate receptor mGluR1. Nature 426:285-291.

Knusel B, Hefti F (1992) K-252 compounds: modulators of neurotrophin signal transduction. J Neurochem 59:1987-1996.

Korkotian E, Segal M (1999) Release of calcium from stores alters the morphology of dendritic spines in cultured hippocampal neurons. Proc Natl Acad Sci USA 96:12068-12072.

Lessmann V, Gottmann K, Malcangio M (2003) Neurotrophin secretion: current facts and future prospects. Prog Neurobiol 69:341-374.

Li HS, Xu XZ, Montell C (1999) Activation of a TRPC3-dependent cation current through the neurotrophin BDNF. Neuron 24:261-273.

Li Y, Jia YC, Cui K, Li N, Zheng ZY, Wang YZ, Yuan XB (2005) Essential role of TRPC channels in the guidance of nerve growth cones by brain-derived neurotrophic factor. Nature 434:894-898.

Li YX, Zhang Y, Lester HA, Schuman EM, Davidson N (1998) Enhancement of neurotransmitter release induced by brain-derived neurotrophic factor in cultured hippocampal neurons. J Neurosci 18:10231-10240.

Lo DC, McAllister AK, Katz LC (1994) Neuronal transfection in brain slices using particle-mediated gene transfer. Neuron 13:1263-1268.

Lu B (2003) BDNF and activity-dependent synaptic modulation. Learn Mem 10:86-98.

McAllister AK, Katz LC, Lo DC (1997) Opposing roles for endogenous BDNF and NT-3 in regulating cortical dendritic growth. Neuron 18:767-778.

McAllister AK, Katz LC, Lo DC (1999) Neurotrophins and synaptic plasticity. Annu Rev Neurosci 22:295-318.

Merritt JE, Armstrong WP, Benham CD, Hallam TJ, Jacob R, Jaxa-Chamiec A, Leigh BK, McCarthy SA, Moores KE, Rink TJ (1990) SK\&F 96365, a novel inhibitor of receptor-mediated calcium entry. Biochem J 271:515522.

Mikoshiba K (1997) The InsP3 receptor and intracellular $\mathrm{Ca}^{2+}$ signaling. Curr Opin Neurobiol 7:339-345.

Mizuno N, Kitayama S, Saishin Y, Shimada S, Morita K, Mitsuhata C, Kurihara H, Dohi T (1999) Molecular cloning and characterization of rat trp homologues from brain. Brain Res Mol Brain Res 64:41-51.

Montell C, Birnbaumer L, Flockerzi V (2002) The TRP channels, a remarkably functional family. Cell 108:595-598.

Poo MM (2001) Neurotrophins as synaptic modulators. Nat Rev Neurosci 2:24-32.

Pozzo-Miller L (2006) BDNF enhances dendritic $\mathrm{Ca}^{2+}$ signals evoked by coincident EPSPs and back-propagating action potentials in CA1 pyramidal neurons. Brain Res 1104:45-54.

Pozzo-Miller LD, Petrozzino JJ, Mahanty NK, Connor JA (1993) Optical imaging of cytosolic calcium, electrophysiology, and ultrastructure in pyramidal neurons of organotypic slice cultures from rat hippocampus. NeuroImage 1:109-120.

Pozzo-Miller LD, Petrozzino JJ, Connor JA (1995) G protein-coupled receptors mediate a fast excitatory postsynaptic current in CA3 pyramidal neurons in hippocampal slices. J Neurosci 15:8320-8330.

Pozzo-Miller LD, Inoue T, Murphy DD (1999) Estradiol increases spine density and NMDA-dependent $\mathrm{Ca}^{2+}$ transients in spines of CA1 py- ramidal neurons from hippocampal slices. J Neurophysiol 81:1404-1411.

Putney Jr JW (2003) Capacitative calcium entry in the nervous system. Cell Calcium 34:339-344.

Rae MG, Irving AJ (2004) Both mGluR1 and mGluR5 mediate $\mathrm{Ca}^{2+}$ release and inward currents in hippocampal CA1 pyramidal neurons. Neuropharmacology 46:1057-1069.

Segal RA, Greenberg ME (1996) Intracellular signaling pathways activated by neurotrophic factors. Annu Rev Neurosci 19:463-489.

Shelton DL, Sutherland J, Gripp J, Camerato T, Armanini MP, Phillips HS, Carroll K, Spencer SD, Levinson AD (1995) Human trks: molecular cloning, tissue distribution, and expression of extracellular domain immunoadhesins. J Neurosci 15:477-491.

Singh BB, Lockwich TP, Bandyopadhyay BC, Liu X, Bollimuntha S, Brazer SC, Combs C, Das S, Leenders AG, Sheng ZH, Knepper MA, Ambudkar SV, Ambudkar IS (2004) VAMP2-dependent exocytosis regulates plasma membrane insertion of TRPC3 channels and contributes to agonist-stimulated $\mathrm{Ca}^{2+}$ influx. Mol Cell 15:635-646.

Smyth JT, Lemonnier L, Vazquez G, Bird GS, Putney Jr JW (2006) Dissociation of regulated trafficking of TRPC3 channels to the plasma membrane from their activation by phospholipase C. J Biol Chem 281:11712-11720.

Stoppini L, Buchs PA, Muller D (1991) A simple method for organotypic cultures of nervous tissue. J Neurosci Methods 37:173-182.

Strubing C, Krapivinsky G, Krapivinsky L, Clapham DE (2001) TRPC1 and TRPC5 form a novel cation channel in mammalian brain. Neuron 29:645-655.

Thastrup O, Cullen PJ, Drobak BK, Hanley MR, Dawson AP (1990) Thapsigargin, a tumor promoter, discharges intracellular $\mathrm{Ca}^{2+}$ stores by specific inhibition of the endoplasmic reticulum $\mathrm{Ca}^{2+}$-ATPase. Proc Natl Acad Sci USA 87:2466-2470

Tozzi A, Bengtson CP, Longone P, Carignani C, Fusco FR, Bernardi G, Mercuri NB (2003) Involvement of transient receptor potential-like channels in responses to mGluR-I activation in midbrain dopamine neurons. Eur J Neurosci 18:2133-2145.

Tyler WJ, Pozzo-Miller LD (2001) BDNF enhances quantal neurotransmitter release and increases the number of docked vesicles at the active zones of hippocampal excitatory synapses. J Neurosci 21:4249-4258.

Tyler WJ, Pozzo-Miller L (2003) Miniature synaptic transmission and BDNF modulate dendritic spine growth and form in rat CA1 neurones. J Physiol (Lond) 553:497-509.

Tyler WJ, Perrett SP, Pozzo-Miller LD (2002a) The role of neurotrophins in neurotransmitter release. The Neuroscientist 8:524-531.

Tyler WJ, Alonso M, Bramham CR, Pozzo-Miller LD (2002b) From acquisition to consolidation: on the role of brain-derived neurotrophic factor signaling in hippocampal-dependent learning. Learn Mem 9:224-237.

Tyler WJ, Zhang XL, Hartman K, Winterer J, Muller W, Stanton PK, PozzoMiller L (2006) BDNF increases release probability and the size of a rapidly recycling vesicle pool within rat hippocampal excitatory synapses. J Physiol (Lond) 574:787-803.

Vanderklish PW, Edelman GM (2002) Dendritic spines elongate after stimulation of group 1 metabotropic glutamate receptors in cultured hippocampal neurons. Proc Natl Acad Sci USA 99:1639-1644.

Vlahos CJ, Matter WF, Hui KY, Brown RF (1994) A specific inhibitor of phosphatidylinositol 3-kinase, 2-(4-morpholinyl)-8-phenyl-4H-1benzopyran-4-one (LY294002). J Biol Chem 269:5241-5248.

Yamamoto N, Kurotani T, Toyama K (1989) Neural connections between the lateral geniculate nucleus and visual cortex in vitro. Science 245:192-194.

Yuste R, Bonhoeffer T (2001) Morphological changes in dendritic spines associated with long-term synaptic plasticity. Annu Rev Neurosci 24:1071-1089.

Zhu X, Jiang M, Birnbaumer L (1998) Receptor-activated $\mathrm{Ca}^{2+}$ influx via human Trp3 stably expressed in human embryonic kidney HEK293 cells. Evidence for a non-capacitative $\mathrm{Ca}^{2+}$ entry. J Biol Chem 273:133-142. 